\title{
Contour Intonation Transfiguration of Declarative Speech by Autistic Children
}

\author{
Ika Septiana \\ Universitas Negeri Surabaya \\ Surabaya, Indonesia \\ ikaseptiana@mhs.unesa.ac.id
}

\author{
Bambang Yulianto \\ Universitas Negeri Surabaya \\ Surabaya, Indonesia \\ bambangyulianto@unesa.ac.id
}

\author{
Kisyani Laksono \\ Universitas Negeri Surabaya \\ Surabaya, Indonesia \\ kisyani@unesa.ac.id
}

\begin{abstract}
The purpose of this paper is to describe contour intonation transfiguration of autistic children's declarative speech. Autistic children's speech is unique when it is compared with normal children's speech. Sometimes the speech of autistic children makes the adult think critically to understand the meaning of the speech. Their phonological abilities are very limited to be understood by others. It is also influenced by the intonation that accompanies the speech. The contour intonation is depicted at the end of the sound or utterance decreased. Contour intonation which is up and downcan be a misinterpretation to understand the meaning of speech of autistic children. Transfiguration of up and down contour intonation may differ even if the meaning of the sentence is the same. This is because autistic children speak with different word choices and sentence structures. They speak naturally and spontaneously, so sometimes they babble at will. The methods used in the data collection are observation and interview. The data is collected by recording autistic children's speech. The data of this research is Indonesian declarative sentences. The data analysis used in the study is qualitative descriptive.
\end{abstract}

Keywords - transfiguration; contour intonation; declarative speech; autistic children

\section{INTRODUCTION}

All human beings have the ability to speak, except those who have incapacity such as the mute or deaf. Speech or speech obtained is gradually according to age [1]. God's given ability to speak to all human beings both normal humans and humans with incapacities. Children born in this world have language skills. Speech skills was received by children from childhood. Normal children and children with incapacities have the skills to speak. Production of words or sentences spoken by children from speech activities is very diverse. Likewise children with incapacities, i.e. children with autism. Speech or sound language that comes out of autistic children can be natural or unnatural. Children with autism can produce natural speech, meaning autistic children produce speech that naturally comes out of his heart and mind without having to imitate or get instructions from others.

Lass (1991) claimed that speaking and listening are two important processes in communication. If the listeners can better understand the content or the message conveyed by the speaker, then the listeners were able to capture sounds or speech delivered. Sounds themselves have no meaning, but in the structure of the language either standalone or combine others, these sounds can carry meaning [2]

Language is a sound system that the linguists have already recognized. Therefore, the main object of linguistic study is the spoken language, the language in the form of the word. The material of language is the sounds of words. An in-depth study of the sounds of speech exists in the study of linguistic branches of phonology [1]

The assumption slavery in generative phonology includes several elements. First, some sound segments and sound classes are more natural than others. Second, some phonological process rules exist that are more natural than other rules. Third, the more natural the elements of the language, the more languages in the world that have these elements. Fourth, the natural element is more quickly controlled by children in the process of language development [3]

Aisjahbana argues that pitch accent is used to express emotional meaning such as happy, sad, deliberate, etc. where a duration accent is used to emphasize important parts of one's sentence. The basic intonation of the declarative sentence consists of two parts. The first part is characterized by a rising pitch, the second is by a falling pitch, and there is a pause between the two [4]

Pane argues that the Indonesian grammar based on 1) the real character of the language (as it is actually spoken), 2) context of a sentence, which is defined in terms of intonation, access and word order, and 3) word classes. 
Methodologically, Pane explicitly states that analysis must begin with the spoken language because the phenomena of accent an intonation can only be clearly observed with it. $\mathrm{He}$ thus rejects most of the earlier works on Indonesian language because the language is written in either Roman or Arabic script [4]

Sentences produced by children with autism have various pressures, intonations, or pauses. Intonation based is on the condition or state of the child. The child's situation also affects the resulting intonation. Sentence of news produced by autistic Childs also has a contour of intonation. Contours intonation is patterned up and down.

\section{METHODS}

The methods used in the data collection are observation and interview. The data are collected by recording autistic children's speech. The data of this research is Indonesian declarative sentences. The data used is a declarative speech of the Indonesian language obtained from the chatter and answers of autistic children of the questions from others. The source of the research is the speech of children with autism. The object of research is transfiguration of contour intonation of declarative speech. The data analysis used in the study is qualitative descriptive. The data analysis used is PRAAT programs [5]

\section{FINDINGS AND DISCUSSION}

The intonation contour transfiguration of autistic children's declarative speech that will be described in this discussion is in a group. Every group has 3-4 sentences from the single word of single word sentence. Every sentence is described as a single word. Then, those single words are developed on the word combination sentence consisted of 2-4 words in a sentence. A single word developed into a combination of word based on a child's natural speech is Hafiz and azan.

The first the declarative sentence produced by autistic children is a single word hafiz. Besides that single word, by using the same word autistic children pronounce a word combination sentence of a single word. The single words uttered in the word combination are watching hafiz and hafiz Quran. Based on the word location, the single words on that word combination are different. It is one of the factors which causes the different intonation contour in the sentence. Moreover, the intonation contour with Pratt program analysis is pulled ups and downs.

\section{1) Hafiz. \\ $21 \mathrm{t} \#$}

Sentence intonation pattern (1) is symbolized by 21 t. Datum (1) by using Pratt program shows that there is a contour with ups and downs pattern drawn on the spectrogram and intonation contour pictures.
PICTURE 1. SPECTOGRAM OF HAFIZ

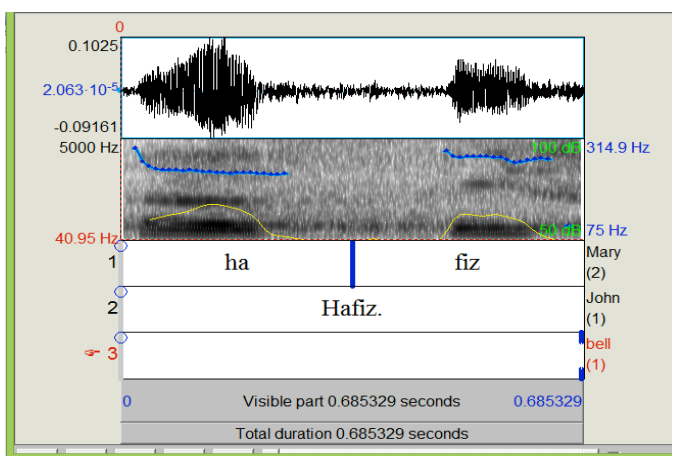

PICTURE 2. INTONATION CONTOUR OF HAFIZ

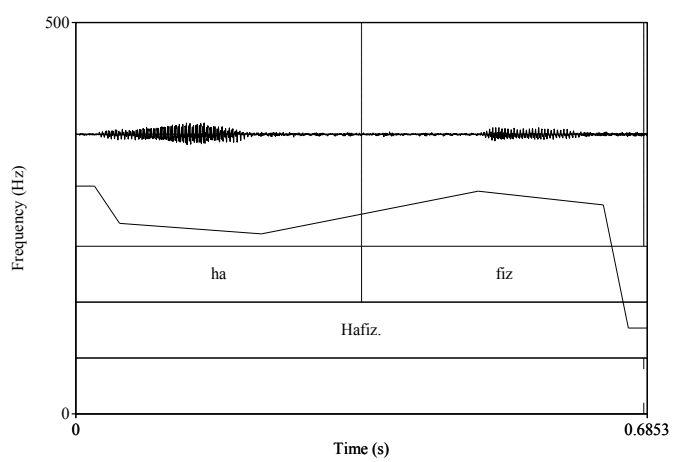

Picture 1 and 2 show that there is a form of ups and downs wave. Like in datum (1), it is shown by intonation pattern of 21t. The intonation contour of picture 2 shows the movement of intonation-high from pressurized syllable to the end of the sentence. Then, intonation contour on picture 1 and 2 are shown by the decreasing line on the intonation contour picture. Intonation contour of the sentence (1) is shown by flat line on the syllable $h a$. Intonation contour appears for getting pressure on the syllable $f i z$.

\section{2) Nonton hafiz.}

\section{$22 / 31 \mathrm{t} \#$}

Sentence intonation pattern (2) is symbolized by 22/ $31 \mathrm{t}$. Datum (2) by using Pratt program shows that there is a contour with ups and downs pattern drawn on the spectrogram and intonation contour pictures.

PICTURE 3. SPECTOGRAM OF NONTON HAFIZ

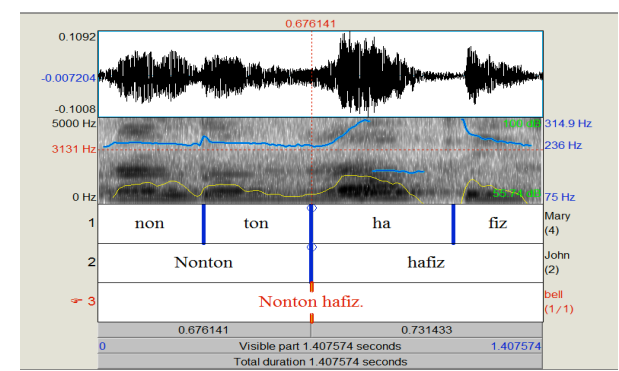


PICTURE 4. INTONATION CONTOUR OF NONTON HAFIZ

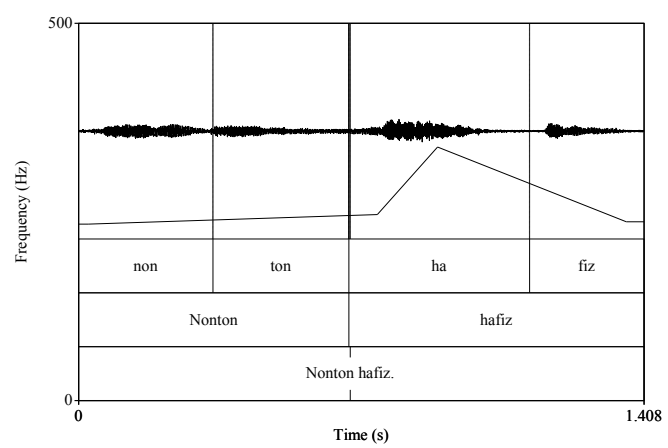

Picture 3 and 4 show that there is form of ups and downs wave. Like in a sentence (2), it is shown by intonation pattern of 22/31t. The intonation contour of picture 4 shows the movement of intonation-high from pressurized syllable in the middle of the sentence until the end. The intonation contour on sentence (2) is shown by the increasing line of the syllable $\underline{h a}$. It is the main contour that describes a pressure existence on the syllable $\underline{h a}$. The contour of intonation also shows the decreasing intonation of the syllable fiz.

\section{3) Hafiz quran}

2 2/ 3 1t\#

Sentence intonation pattern (3) is symbolized by 22/ 31 t. Datum (3) by using Pratt program shows that there is a contour with ups and downs pattern drawn on the spectrogram and intonation contour pictures.

PICTURE 5. SPECTOGRAM OF HAFIZ QURAN

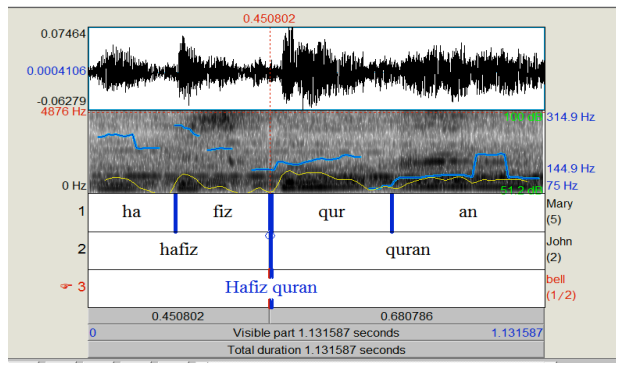

PICTURE 6. INTONATION CONTOUR OF HAFIZ QURAN

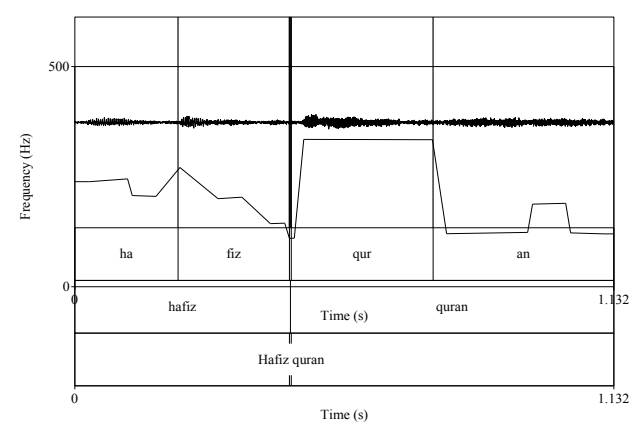

Picture 5 and 6 show that there are form of ups and downs wave. As in sentence (3), it is shown by the pattern of intonation $2231 \mathrm{t}$. The intonation contour of picture 6 shows the movement of intonation-high from pressurized syllable in the middle of the sentence until the end. Thus, the intonation contour of sentence (3) is shown by the increasing line on the syllable qur. It is a main contour that describes a pressure existence on the syllable qur. The contour of intonation also shows the decreasing intonation of the syllable $\underline{a n}$.

Sentence (1)-(3) are the declarative sentences with the different word arrangement. Sentence (1) is a single word sentence. It means that the sentence only has one word that becomes the main word. That single word is attached to combination word, as in sentence (2) and (3). Sentence (2) is a word combination sentence that has a single word from the sentence (1) which is Hafiz located at the end of the sentence. Data (3) is similar to data (2). Both of them are word combination sentences. However, the location of the single word from data (3) is different from data (2). The single word location on sentence (3) is at the beginning of the sentence followed by another word combination connected to the declarative sentence.

Sentence (1) is a response to the question Nonton apa? The autistic children answered the question in a relaxed conversation. The children answer the question briefly consisting of one word. The sentence of the autistic children's answer is a single word sentence. Hafiz is a television program in one of Indonesian private television. It is about hafiz (memorizing Al-Qur'an). The children often watch this program so that the autistic children know the word of hafiz. Hafiz is not only said for once or twice but in many times the children say the hafiz word. In the next speech, it is pronounced sentence (2). That question is quite long, i.e. nonton apa? and the children answered by saying nonton hafiz. In sentence (2), there is a word combination which is nonton. That word is removed from a sentence (1) and not pronounced by autistic children. The children speak by using the brief sentence that only consists of one word. After discussing a sentence (2), there is a sentence (3) which is an explanatory sentence to clarify the purpose of autistic children. The sentence (3) is the answer to the question hafiz apa?

The intonation contour of word azan is on the sentence (4) until (6) Furthermore, the main contour is shown on the different pressure.

The intonation contour of the word hafiz is on the sentence (1) until (3). Intonation contour hafiz drawn on the intonation contour pictures number 8,10 , and 12 show that there is the intonation contour transfiguration. Furthermore, the main contour is also shown on the different pressure. The intonation pattern of the word hafiz in a sentence (1) is 21t, in the sentence (2) is $31 \mathrm{t}$, and in the sentence (3) is 22. Based on those facts, the intonation contour and the intonation pattern is different despite with the same single word.

The second group of declarative sentence produced by autistic children is a single word azan. Besides that single word sentence, the autistic children also say the word combination sentence that consists of the single word on the word azan. That single word is pronounced in the word combination 
sentences. Those are kadang azan and aku mau azan sendiri. The intonation contour of those sentences is different because of the differences of single word location. It describes that there is the intonation contour transfiguration on the second declarative sentence.

\section{4) Azan \\ 2 1t\#}

Sentence intonation pattern (4) is symbolized by $21 \mathrm{t}$. Datum (1) by using Pratt program shows that there is a contour with ups and downs pattern drawn on the spectrogram and intonation contour pictures.

PiCTURE 7. SPECTOGRAM OF $A Z A N$

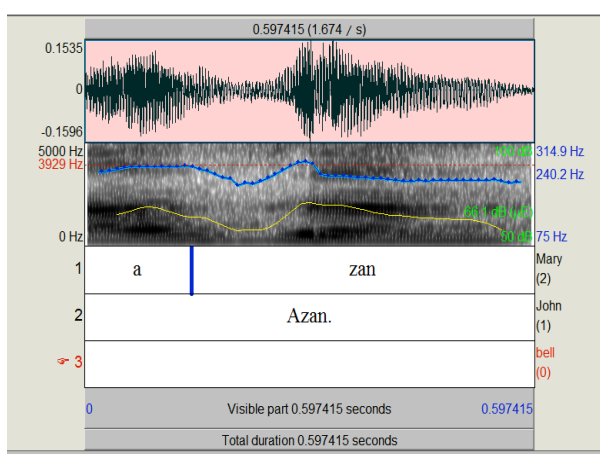

PICTURE 8. INTONATION CONTOUR OF $A Z A N$

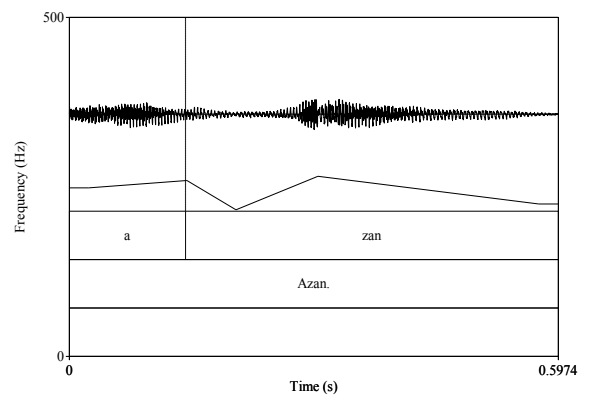

Picture 7 and 8 show that there is a form of ups and downs wave. As in sentence (4), it is shown by the pattern of intonation 21t. The intonation contour of picture 8 shows the high movement of ups and downs intonation of the last syllable. The contour of intonation also shows the decreasing intonation of the syllable zan.

5) Kadang azan.

$22 / 31 \mathrm{t} \#$

Sentence intonation pattern (5) is symbolized by 22/ $31 \mathrm{t}$. Datum (5) by using Praat program shows that there is a contour with ups and downs pattern drawn on the spectrogram and intonation contour pictures.
PICTURE 9. SPECTOGRAM OF KADANG AZAN

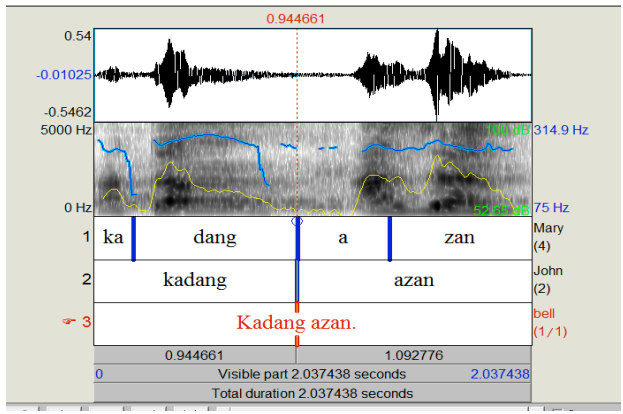

PICTURE 10. INTONATION CONTOUR OF KADANG AZAN

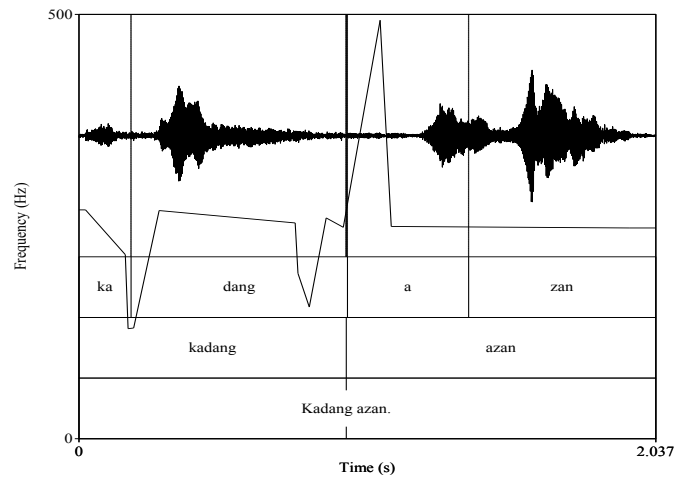

Picture 9 and 10 show that there is a form of ups and downs wave. As in sentence (5), it is shown by the pattern of intonation 22/31t. The intonation contour of picture 10 shows the movement of intonation-high from pressurized syllable in the middle of the sentence until the end. The intonation contour of the sentence (3) is shown by the increasing line on the syllable $a$. It is a primary contour that is drawn on that syllable. The intonation contour picture also shows the decreasing intonation of the syllable zan.

\section{6) Aku mau azan sediri.}

\section{$23 / 231 / 32 / 231 \#$}

Sentence intonation pattern (6) is symbolized by $23 / 23 / 32 /$ 231. Datum (6) by using Pratt program shows that there is a contour with ups and downs pattern drawn on the spectrogram and intonation contour pictures.

PICTURE 11. SPECTOGRAM OF AKU MAU AZAN SENDIRI

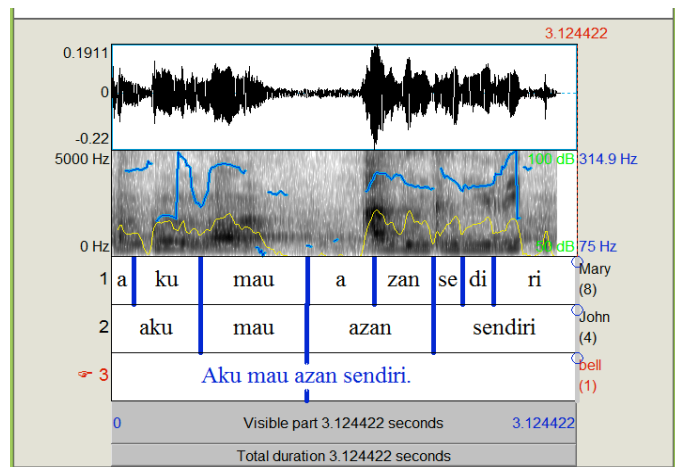


PICTURE 12. INTONATION CONTOUR OF AKU MAU AZAN SENDIRI

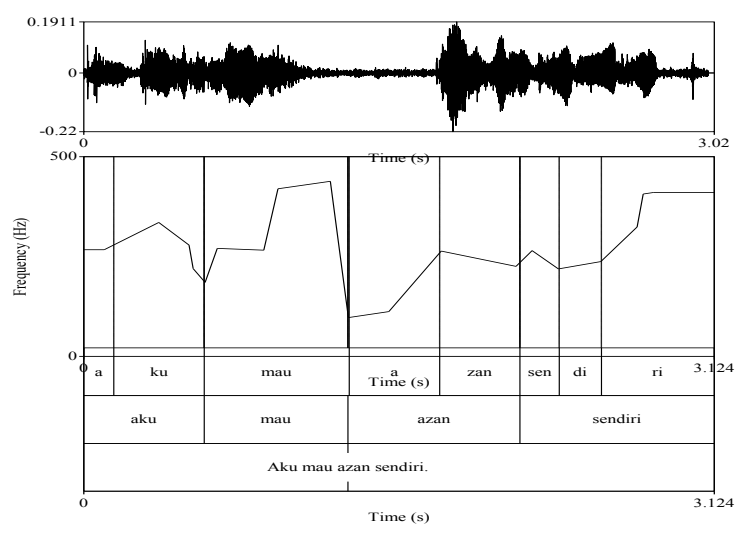

Picture 11 and 12 show that there is a form of ups and downs wave. As in sentence (6), it is shown by the pattern of intonation $23 / 231 / 32 / 231$. The intonation contour of picture 12 shows the movement of intonation-high from pressurized syllable in the middle of the sentence until the end. The intonation contour of the sentence (6) is shown by the increasing and decreasing lines in the word $\underline{\mathrm{mau}}$ and has an intonation pattern 23. It describes the main contour that shows a pressure in the middle of the sentence. The intonation contour picture also shows the decreasing intonation of the syllable $a$ of the word azan which has intonation pattern 32 and the syllable of $\underline{r i}$ of the word that gets intonation pattern 231 .

The sentence (4)-(6) are declarative sentences with the different word organization. Sentence (4) is a single word sentence. It means that the sentence only has one word that becomes the main word. That single word is attached to combination word, as in the sentence (5) and (6). Sentence (5) is a word combination sentence that has a single word from a sentence (4). It is azan. Sentence (5) is similar to data (6). Both are word combination sentences with the different location of the single word. The single word location of datum (5) is in the end of the sentence. While the single word location of datum (6) is in the middle of the sentence started and followed by another word combination connected to the declarative sentence.

The intonation contour of word azan on the sentence (4) until (6) drawn on the intonation contour pictures number 8 , 10 , and 12 show that there is the intonation contour transfiguration. Furthermore, the main contour is shown on the different pressure. The intonation pattern of the word azan in the sentence (4) is $21 \mathrm{t}$, in the sentence (5) is $31 \mathrm{t}$, and in the sentence (6) is 32 . Based on those facts, the intonation contour and the intonation pattern is different despite with the same single word.
According to the pictures, the intonation pattern drawn in the sentence (1) until (6) include a group of pause or more. One group of pause has the main contour and combination of a pra contour and the main contour. The contour in the sentence (1) until (6) is started by high intonation. Those intonations-high have the pattern just like what has been described in each sentence and picture.

The spectrograms and intonation contours by using Pratt program in the picture 1 untill2 describe the ups and downs lines which are different. The increasing pictures describe the movement of high stopping line of high intonation. While the decreasing pictures describe the high rising movement of low intonation that is drawn on the syllables. It also shows the pressure of the sentence like picture 6 . The intonations-high which is up and down in the picture of Pratt program is started from pressurized syllable to the end of pause group.

\section{CONCLUSION}

Based on the picture of intonation contour by using Pratt program, it is shown that there is an intonation contour transfiguration of the autistic children's declarative sentence. The change of intonation contour is caused by the location of the single word which is different. The declarative sentence includes single word sentence and word combination sentence. The single word as the main word located at the beginning of a sentence, in the middle of a sentence and at the end of the sentence shows that the ups and downs intonation contour is different.

Intonation contour in the single word has a change based on the location. Even, the single word located at the beginning of a sentence is not necessarily similar. It is caused when producing words or pronouncing sentences, autistic children use the different intonation according to the children's expression. Children's intonation also describes the purpose of those children. Intonation contour transfiguration is drawn on the different intonation pattern. It is influenced by the differences of main words location and main contour. Moreover, it is also caused by the syllables pronounced by the children which have ups and downs intonation.

\section{REFERENCES}

[1] M. Muslich, Fonologi Bahasa Indonesia. Jakarta: Bumi Aksara, 2008

[2] S. Afriani, An Introduction to Linguistics. Yogyakarta: Ombak, 2015.

[3] B. Yulianto, Perkembangan Fonologi Bahasa Anak. Surabaya: University Press, 2009.

[4] A. Halim, Intonation: In Relation to Syntax in Bahasa Indonesia. Jakarta: Djamban, 1974.

[5] P. v. Lieshout, "Praat Short Tutorial V," University of Toronto, 2003. 